\title{
LIBERDADE DE EXPRESSÃO E FAKE NEWS: MECANISMOS DE REPARAÇÃO E ACESSO À JUSTIÇA
}

\section{Luiz Fernando Bellinetti* Ricardo Benvenhu**}

\section{Resumo}

O trabalho teve como objetivo analisar a correlação entre a liberdade de expressão e fake news. Para tanto, utilizou-se de pesquisa bibliográfica, aplicando-se o método dedutivo. Constatou-se a necessidade da precisa definição dos contornos do que seja fake news para que a persecução dessa conduta pelos órgãos estatais não se converta em supressão à liberdade de expressão. Também se verificou que este direito somente deve sofrer mitigação quando o seu exercício for manipulado para lesar bens juridicamente protegidos, notadamente transindividuais, oportunidade em que os colegitimados poderão utilizar os instrumentos dos microssistemas de tutela coletiva para garantia de acesso à justiça.

Palavras-chave: Liberdade de Expressão. Estado Democrático de Direito. Fake News. Acesso à Justiça. Mecanismos de Reparação.

\section{FREEDOM OF SPEECH AND FAKE NEWS: MECHANISMS OF REPARATION AND ACCESS TO JUSTICE}

\begin{abstract}
This work analyse the correlation between freedom of speech and fake news. It used an bibliographic research, applying the deductive method. It has been found the need of a definition of the outlines of what is fake news for that the persecution of this conduct by state agencies does not become a suppression of rights. It was also verified that this right should be mitigated when its exercise is an instrument to harm legally protected assets, notably transindividuals, an opportunity in which the collegitimates will be able to use the instruments of collective tutelage microsystems to guarantee access to justice.
\end{abstract}

Keywords: Freedom of Speech. Democratic State of Law. Fake News. Access to justice. Remedies for Damages.

\section{INTRODUÇÃO}

\footnotetext{
1 Mestre em Direito pela UEL e Doutor em Direito pela PUC-SP. Procurador de Justiça Aposentado. Advogado. Professor dos Cursos de graduação e pós-graduação em Direito da UEL. E-mail: luizbel@uol.com.br; endereço: Departamento de Direito Privado/CESA/UEL. Rodovia Celso Garcia Cid, PR-445, Km 380 - Campus Universitário, Londrina - PR, 86057-970.

*** Especialista pela Fundação Escola do Ministério Público do Estado do Paraná. Mestrando em Direito Negocial pela Universidade Estadual de Londrina. Promotor de Justiça do Estado do Paraná, lotado na Promotoria de Proteção ao Patrimônio Público da Comarca de Londrina. E-mail: rbenvenhu@yahoo.com.br; endereço postal: Rua Capitão Pedro Rufino, ${ }^{\circ}$ 605, CEP 86.015-700, Londrina/PR.
} 
A Constituição Federal de 1988 rompeu com uma série de comportamentos ilegais e nocivos praticados durante o regime opressor anterior, em que se pregava a censura, repressão, perseguição e supressão de direitos. O modelo constitucional, concretizado a partir do Estado Democrático de Direito, tutelou enfaticamente a liberdade de expressão e a pluralidade de ideias, constituindo-se em pilares da democracia.

A despeito desta extraordinária conquista, o desenvolvimento tecnológico que permeia as relações humanas propicia a disseminação das notícias em velocidade absolutamente incomum, notadamente as inverídicas, conhecidas como fake news.

Nesse viés, um dos objetivos desde estudo é verificar se os valores tidos por fundamentais numa sociedade democrática, como a liberdade, igualdade e tolerância, podem sofrer limites quando confrontados com estas notícias fraudulentas. E, em especial, será necessário definir com exatidão o conceito de fake news, inclusive se, no plano jurídico, toda e qualquer propagação de informação falsa admite a responsabilização do indivíduo, a ponto de legitimar a supressão de garantias tão essenciais. Almeja-se, por fim, a partir da caracterização inconteste do que se considera fake news, elucidar os mecanismos para a prevenção e a repressão como forma de tutelar o interesse transindividual dos lesados e garantir o acesso à justiça.

Tal estudo é baseado em pesquisa legislativa, doutrinária e jurisprudencial, com a utilização do método dedutivo.

\section{LIBERDADE DE EXPRESSÃO}

O direito à liberdade de expressão trata-se de garantia fundamental do cidadão. Nela está contido o ato volitivo do ser humano capaz de exteriorizar o seu pensamento de forma livre, sem receio de coerção, podendo ser materializada de múltiplas formas.

É fato induvidoso que a tutela desse bem jurídico de fundamental importância (liberdade) sofreu, durante os diversos momentos históricos, no Brasil e no mundo, considerável evolução, concretizada em decorrência de inúmeros fatores políticos, sociais e econômicos que motivaram e até exigiram do legislador constituinte um tratamento que melhor se compatibilizasse com as novas ordens de valoração.

Necessário consignar que a Declaração Universal dos Direitos do Homem, de 1948, representou significativo avanço sobre a matéria, porque ao implementar a 
internacionalização dos direitos humanos, cada nação tratou de positivá-los como instrumento catalisador do direito à liberdade.

Por outro lado, no Brasil, nem sempre o direito à liberdade de expressão encontrou um solo propício de propagação. A censura, impulsionada pela ditadura militar, preponderava sobre os direitos fundamentais do indivíduo. O Estado, imbuído de escusos interesses governamentais, controlava a autonomia da vontade do cidadão, impondo-lhe o silêncio.

Esse triste período impunha, ainda, a censura didática, em que as escolas e as universidades eram colocadas como meio de propagação da ditadura militar, a imprensa era controlada e alguns artistas foram exilados por comportamento considerado ofensivo aos valores da época.

Sobre o tema, assevera Luís Roberto Barroso (2001, p. 131):

A censura jamais se apresenta como instrumento da intolerância, da prepotência ou de outras perversões ocultas. Ao contrário, como regra, ela destrói em nome da segurança, da moral, da família, dos bons costumes. $\mathrm{Na}$ prática, todavia, oscila entre o arbítrio, o capricho, o preconceito e o ridículo. Assim é porque sempre foi.

Nesse ambiente pós ditadura, diante da proeminente necessidade de se redemocratizar o Brasil, adveio a Constituição Federal de 1988, em que se rompe com as nefastas práticas para consagrar os direitos fundamentais do cidadão. Assim é que, logo no artigo $1^{\circ}$, caput, preceitua-se que a República se constitui em Estado Democrático de Direito. Esse postulado, dotado de incomum densidade, evoca uma série de conteúdos a ela inerentes, que conferem ao intérprete verdadeiras barreiras normativas de interpretação.

Assim, pode-se afirmar que a liberdade de expressão, como garantia máxima fundamental, não se encontra aglutinada em único dispositivo mas alastrada ao longo do texto constitucional, tais como: 1) art. $5^{\circ}$, inciso IV - liberdade de manifestação do pensamento -; 2) art. $5^{\circ}$, inciso IX - liberdade de expressão de atividade intelectual, artística, científica e de comunicação, independentemente de censura ou licença -; 3) art. $5^{\circ}$, inciso XIV - direito à informação e garantia do sigilo da fonte -; 4) art. 220, caput - garantia da manifestação do pensamento, da criação, da expressão e informação, sob qualquer forma e veículo -; 5) art. $220, \S 1^{\circ}$ - liberdade de informação jornalística em qualquer veículo de comunicação social -; 6) art. $220, \S 2^{\circ}$ - proibição de qualquer censura de natureza política, artística ou ideológica.

Como se percebe, revela-se de suma importância preservar a liberdade de expressão e a pluralidade de ideias, sob pena de sufragar o Estado Democrático de Direito. 
Força reconhecer que o direito à liberdade de expressão também abrange a liberdade de informação, que, por sua vez, compreende a liberdade de informar e o direito de ser informado. Neste aspecto, trata-se de valiosa conquista que permite ao cidadão, como verdadeiro detentor do poder estatal, a um só tempo, exercer o controle dos atos públicos e conhecer os fatos noticiados pelos meios de comunicação.

A liberdade de informar, de outro turno, conecta-se substancialmente à liberdade de imprensa, que detém o direito de trazer matérias e conteúdos para o público em geral. Importante asseverar, neste aspecto, a proeminente necessidade dos órgãos de comunicação noticiarem a informação verdadeira. Assim, reputa-se inadmissível que a imprensa municie a população com inverdades, notadamente pelo elevado potencial de formar opinião e influenciar as pessoas.

Desse modo, inquestionável que a veiculação de notícia falsa, desvirtuada da seriedade, que objetiva propagar fatos incoerentes, parciais e irreais, não deve obter a chancela constitucional, o que possibilita a responsabilidade do jornalista.

De acordo com Guiomari Garson da Costa Garcia (2003, p. 288-289):

Essa veracidade diz respeito à verdade subjetiva, que consiste no dever de diligência em busca da idoneidade da fonte dos fatos e consequente seriedade da notícia antes de qualquer divulgação, uma vez que a verdade objetiva não existe, pois está unicamente na atitude espiritual do observador e não na objetividade das coisas. Portanto, a veracidade da informação não constitui qualidade desta, mas diz respeito à atitude diligente do sujeito com relação à notícia a ser divulgada.

Nesse ponto, a liberdade de informação jornalística se distingue da liberdade de expressão propriamente dita, que por conter conceitos axiológicos, prescinde tanto da imparcialidade quanto da veracidade. Deve-se avaliar, todavia, se exercida dentro dos limites admissíveis.

Nesse sentido, oportuna a lição de Castanho de Carvalho (1999, p. 24):

Todos os doutrinadores citados, mesmo os que, em maioria, adotam uma disciplina comum entre a expressão e informação, deparam-se com, pelo menos, uma distinção importante entre os dois institutos: a veracidade e a imparcialidade da informação. E é, justamente, em razão dessa distinção fundamental que se deve pensar em um direito de informação que seja distinto em sua natureza da liberdade de expressão.

Dito isto, convém asseverar que a liberdade de expressão, muito embora ganhe ares de supremacia, pode sofrer limites para proteger outros direitos fundamentais, de jaez constitucional. É certo que no caso concreto, se existir colisão entre princípios garantidores de 
direitos fundamentais há de se ponderá-los, utilizando-se, para tanto, o princípio da proporcionalidade. Não se deve renegar, por óbvio, outros bens jurídicos essenciais para salvaguardar a liberdade de expressão, como a vida, a honra, a personalidade, entre outros. É necessário enfatizar, contudo, que se trata de hipótese excepcional que deve ser verificada caso a caso, com a devida cautela para não promover censura prévia de uma garantia extraordinária.

Nas palavras de Norberto Bobbio (1992, p. 24), na maioria das situações em que está em causa um direito do homem, ao contrário, ocorre que dois direitos igualmente fundamentais se enfrentem, e não se pode proteger incondicionalmente um deles sem tornar o outro inoperante. Basta pensar, para ficarmos num exemplo, no direito à liberdade de expressão, por um lado, e no direito de não ser enganado, excitado, escandalizado, injuriado, difamado, vilipendiado, por outro.

Nessa linha de raciocínio, o próprio constituinte estabeleceu, ao longo do texto, limites à liberdade de expressão, como se percebe no próprio art. $5^{\circ}$, incisos: IV - é livre a manifestação do pensamento, sendo vedado o anonimato; V - é assegurado o direito de resposta, proporcional ao agravo, além da indenização por dano material, moral ou à imagem; e X - são invioláveis a intimidade, a vida privada, a honra e a imagem das pessoas, assegurado o direito à indenização pelo dano material ou moral decorrente de sua violação, sem descurar da tutela a outros bens e valores essenciais, como o devido processo legal, a proteção à saúde e a própria igualdade.

Portanto, a Constituição Federal tratou de resguardar outros direitos de suma relevância para a sociedade. Cumpre esclarecer que o indivíduo detém a garantia de se manifestar sobre qualquer assunto e tema, mas pode eventualmente ser responsabilizado quando exceder totalmente os limites do aceitável, tratando-se de medida esporádica.

Por esta razão, não se pode olvidar que a sociedade atual é pluralista, com divergência de ideias, valores e opiniões, tornando legítima a proteção constitucional para preservar a liberdade de expressão dos indivíduos. Assim, censurar o ser humano por suas palavras e opiniões dissonantes com a maioria privilegia a nefasta prática ditatorial, absolutamente incompatível com as diretrizes constitucionais.

Nesse contexto, é essencial a preservação do pluralismo; contudo, não basta a sua idealização teórica, sendo imperioso que a sociedade busque mecanismos para a convivência harmônica. 
Forçoso reconhecer, nessa seara, que o tema hate speech (discurso de ódio) ganha especial relevo no contexto atual, em que a sociedade se encontra ideologicamente dividida e polarizada. A propósito, apesar de o tema ser passível de orientação dissonante, entende-se que a liberdade de expressão não implica em autorização para que o cidadão, por intermédio de suas ideias, cometa ilícitos, como as que disseminam apologia ao racismo, justamente por afrontar valores inerentes à convivência social, que são protegidos pela Constituição Federal, como a igualdade e a dignidade da pessoa humana.

Por oportuno, Daniel Sarmento (2006, p. 58) trata do tema com propriedade:

o caminho adotado pelo Brasil, que aceita as restrições à liberdade de expressão voltadas ao combate do preconceito e da intolerância contra minorias estigmatizadas, parece-nos correto, tanto sob o ponto de vista jurídico como moral. Ele está em plena consonância com a normativa internacional sobre direitos humanos e com a jurisprudência constitucional da maioria das democracias liberais modernas - os Estados Unidos, neste particular, é que representam a exceção. Contudo, num país como o nosso, em que a cultura da liberdade de expressão ainda não deitou raízes, há que se ter cautela e equilíbrio no percurso deste caminho, para que os nobres objetivos de promoção da tolerância e de defesa dos direitos humanos dos excluídos não resvalem para a perigosa tirania do politicamente correto.

Assim, não é demais lembrar que a liberdade de expressão deve sempre ser almejada no Estado Democrático de Direito, apenas admitindo que o Estado a restrinja quando a manifestação se mostrar totalmente irrazoável.

\section{FAKE NEWS}

Censurar o ser humano por suas palavras, opiniões, críticas, de acordo com a sua livre orientação, além de ser antidemocrático, atenta severamente contra os preceitos estabelecidos na Constituição Federal. O pluralismo social revela-se salutar para a consagração do Estado Democrático de Direito, notadamente no campo político e econômico em que a difusão de opiniões deve servir para o aperfeiçoamento de determinado tema. Nessa medida, é desnecessário enfatizar que a divergência de ideias amplia o campo de visão de ambos os lados. Logo, o debate com posições antagônicas e contraditórias enriquece o ambiente democrático.

É importante asseverar, todavia, que a liberdade de expressão, tão almejada pelo constituinte, deve ser exercida dentro do espectro de legalidade, vale dizer, coíbe-se a manifestação que transborde os limites legais. 
Observe-se, nesse ponto, que os direitos e garantias fundamentais, dentre os quais se insere a liberdade de expressão, não se revestem de caráter absoluto. Há limitação de ordem constitucional, a fim de que esta seja empregada para fins legais, legitimados pelo direito, sob pena de subverter a essência protetiva.

Nessa vertente, reputa-se inadmissível que o autor se valha desta garantia para cometer crimes ou mesmo atacar determinados grupos sociais tutelados pelo constituinte. Assim, verificar quais os limites e contornos desta liberdade, notadamente se a divulgação de fake news encontra-se dentro do espectro da proteção constitucional, torna-se essencial para o deslinde desse trabalho.

É claro que compreender o conceito e o alcance do fenômeno é fundamental, principalmente no mundo contemporâneo, marcado pela velocidade absolutamente incomum de propagação de notícias e informação.

Num primeiro momento, necessário destacar que a divulgação de "boatos" não pode ser considerada recente. Basta pensar nas diversas teorias conspiratórias da humanidade que propagaram sem qualquer base consistente, ou mesmo nos jargões que marcaram época, tais como "o homem não pisou a lua", os quais persistem ao longo do tempo. Evidente que o surgimento das inovações tecnológicas, como a internet e a globalização da sociedade massificada tem auxiliado na disseminação das notícias.

Sobre o tema, Marco Antônio Souza Alves e Emauella Ribeiro Halfeld Maciel (2020):

"As fake news não envolvem necessariamente uma ação dolosa, um ato consciente de deturpação da realidade e de enganação. Trata-se de uma ação engajada em uma guerra, uma informação que é consumida, produzida e compartilhada em razão da função que desempenha no combate, corroborando determinada narrativa ou enfraquecendo a narrativa inimiga. É claro que muitas ações intencionalmente enganadoras também terão lugar nesse contexto (...) Via de regra, as fake news encontram seu motor não no desejo de negar a verdade, mas sim na vontade de vencer a disputa a qualquer preço, mesmo que para isso seja preciso falsear a realidade. As pessoas deixam de se perguntar se a notícia é verdadeira ou falsa. Estão ainda menos preocupadas se os fatos estão bem assentados ou se a fonte é confiável. A única coisa que importa é se a notícia favorece sua posição em um contexto polarizado. Assim, produzimos e fazemos circular informações de maneira entrincheirada, usando notícias e manchetes como armas no meio de um campo de batalha".

Nessa linha, não parece adequado considerar como fake news qualquer divulgação de notícia inverídica, sem a verificação de seus pressupostos. Necessário, portanto, identificar e distinguir algumas condutas. 
Para cumprir o propósito deste trabalho, não se pode prescindir da análise criteriosa da casuística a fim de que o Estado não esvazie o direito individual do cidadão. Nesse prisma, forçoso reconhecer que a difusão de ideias manifestadas em determinado momento histórico é fundamental ao ambiente democrático. Podar a livre manifestação de pensamento, ainda que expressada pela minoria e contrária à posição dominante de um determinado segmento, deslegitima o princípio democrático e, em última análise, o próprio Estado Democrático de Direito.

Nessa vertente, inadmite-se a intolerância às posições minoritárias, mesmo que tidas como inverídicas por uma gama de pessoas. O tema ganha relevo em relação a Pandemia Covid/19 vivenciada nos dias atuais, na medida em que se nota a tentativa por parte de alguns críticos de cercear previamente o pensamento divergente que não se coadune com determinado grupo ou setor.

Observe-se, nessa linha, que muitas vezes a conceituação sobre o que seria notícia verídica ou falsa identifica-se com a aptidão partidária das pessoas, revelando-se demasiadamente subjetiva. Anote-se que a verificação isenta e imparcial sobre a veracidade da notícia torna-se essencial para aquilatar os limites propostos da liberdade de expressão. É fato que num Estado Democrático de Direito não se deve vedar a difusão de opiniões por questões políticas, justamente porque o cidadão age dentro do espectro de liberdade garantido pela Constituição Federal. Claro que se parte do princípio que a notícia divulgada não ofenda bens jurídicos relevantes.

Assim, verifica-se, por exemplo, que a propagação de notícias sobre o denominado "tratamento precoce no combate ao Covid/19" tem gerado enorme polêmica. Enquanto a sociedade médica brasileira, por meio do Boletim 02/2021 (G1, 2021), mudou recentemente de orientação e afastou a eficácia de certos medicamentos, um grupo de médicos, por intermédio do Manifesto III (Médicos pela Vida, 2021), defendeu a utilização destes mesmos medicamentos no tratamento precoce, ao passo que o Conselho Federal de Medicina se manifestou no sentido da autonomia dos médicos no tratamento de seus pacientes (CFM, 2020). Diante de tais considerações, em que há divergência dentro da própria classe especializada, parece ser evidente que tais divulgações, sobre um ou outro ponto de vista, não podem ser caracterizadas como fake news. Vale dizer, se nem mesmo a classe médica converge a respeito do tema, exigir do cidadão que se abstenha de disseminar a notícia que lhe interessa não parece razoável. Nesse ponto, cada cidadão tem o direito constitucional de 
decidir livremente sobre qual posição adotar e se expressar de acordo com ela, porque a carta política consagra a liberdade de crença.

Note-se que a ausência de unanimidade se afigura absolutamente salutar ao desenvolvimento de ideias, ainda que aparenta refletir determinada hipótese teratológica de dado momento. Reputa-se absolutamente inadmissível a possibilidade discursiva de controle prévio de discursos no campo social. A livre circulação de manifestações lícitas deve ser almejada como ponto fulcral na atual concepção de Estado Democrático de Direito, voltada à promoção humana e desenvolvimento das potencialidades pessoais.

Portanto, a bem da verdade, a conduta do indivíduo de replicar a notícia, ainda que desvirtuada para alguns, mesmo tida por descontextualizada ou repugnante, com o objetivo de difundir uma ideia ou opinião com a qual simpatiza, trazendo-lhe certo conforto, especialmente quando relacionada à questão política, jamais pode ser considerada como fraudulenta a ponto de limitar a sua divulgação. Assim, entende-se inconcebível, no plano jurídico, estender tal comportamento às sanções materializadas pelo direito.

De igual sorte, ainda que o sujeito compartilhe notícia falsa, absolutamente incoerente, não há como enquadrá-lo como "propagador de fake news", sendo necessário verificar os contornos desta divulgação, que serão adiante abordados.

Há, atualmente, diversos projetos de lei que visam criminalizar a disseminação de fake news. É cediço que o legislador, ao descrever o modelo de injusto típico, deve prever tipos penais determinados, com a magnitude de injusto culpável. Assim, diferenciar e selecionar a conduta que divulgue notícia falsa, com seus requisitos, torna-se essencial para não criar tipos penais inconstitucionais, pela violação ao princípio da liberdade de expressão.

O Congresso Nacional deve agir consciente de seu papel de protetor dos direitos fundamentais. As denominadas fake news devem ser combatidas, não somente na seara cível mas penal, por intermédio da utilização séria e necessária do direito penal.

Por óbvio que a análise quanto ao conteúdo inverídico da notícia exige do intérprete uma verificação isenta e imparcial se, de fato, o agente propagou conteúdo sabedor de sua não autenticidade.

Portanto, nessa linha de raciocínio, o conceito de fake news que melhor se compatibiliza com os ditames constitucionais pode ser extraído das palavras do Procurador do Estado do Rio de Janeiro, Gustavo Binenbojm (2020): "são mensagens falsas construídas e divulgadas de maneira consciente e deliberada, mediante o uso de artifícios fraudulentos, com o objetivo de desinformar e causar danos a pessoas, grupos e instituições”. 
Assim, entende-se que as fake news devem, necessariamente, trazer três elementos: a) mensagens falsas, b) uso de artifícios fraudulentos, c) objetivo deliberado de causar dano, material ou moral.

Nessa ótica, apenas a falsidade da informação, isoladamente, não tem o condão de abranger tal conceituação, ou ainda, ausente um ou mais elementos não há como se enquadrar tal conduta em um conceito jurídico de fake news.

Feitas essas considerações, é de se concluir que a liberdade de expressão somente pode ser relativizada quando a conduta do agente importar em ilicitude penal e mesmo assim, não prescinde da análise subjetiva e demais elementos caracterizadores já tratados, uma vez que, neste caso, o Estado tipificou comportamentos reprováveis de elevada danosidade social. De igual sorte, muito embora não se considere o "hate speech" como fake news, entende-se que o discurso odioso, lastreado na intolerância e preconceito, também não pode ser tutelado pela liberdade de expressão, notadamente porque incompatível com o regime jurídico da dignidade da pessoa humana e a adesão pelo Estado Democrático de Direito, de natureza constitucional (CF, art. $\left.3^{\circ}\right)$.

Evidentemente há uma questão importante que é definir claramente o que pode ser interpretado como discurso de ódio a fim de que não se torne um termo vago e impreciso a ser utilizado ao bel prazer do intérprete e com fundamento em ideologias pessoais. Trata-se de um tema que também escapa aos objetivos do presente trabalho.

Desse modo, como já ressaltado, inadmite-se a censura prévia como forma de limitar uma opinião ou pensamento, afinal estas condutas foram praticadas de forma constante na Ditadura Militar e abolidas pelo constituinte.

Nas palavras de Daniel Sarmento (2019, p. 83):

[...] quando o exercício de um direito conflita com a dignidade da pessoa humana de um terceiro - o que, no mais das vezes, envolve a tensão entre dois direitos fundamentais diferentes, ambos com algum conteúdo de dignidade - deve-se recorrer a ponderação de interesses para a solução de colisão. Essa ponderação pode ser feita de modo abstrato pelo legislador, ou pode ser realizada no caso concreto pelo intérprete-juiz ou não.

Oportuno observar, nesse sentido, que o Supremo Tribunal Federal, por intermédio do Habeas Corpus $n^{\circ}$ 82.424-2, Rio Grande do Sul, em 17.09.2003, de relatoria do Ministro Celso de Mello (STF, 2003), decidiu pela relativização do direito fundamental a liberdade de expressão quando existe uma manifestação que transborde os limites legais, substancialmente por afetar a dignidade da pessoa humana. 
Sedimentada essa orientação, no sentido de que a liberdade de expressão não detém primazia absoluta, o Supremo Tribunal Federal, recentemente, instaurou o inquérito judicial $n^{\text {o } 4.781 / D F, ~ c u j o ~ o b j e t o ~ e ́ ~ a ~(B R A S I L, ~ 2020): ~}$

\begin{abstract}
investigação de notícias fraudulentas (fake news), falsas comunicações de crimes, denunciações caluniosas, ameaças e demais infrações revestidas de animus caluniandi, diffamandi ou injuriandi, que atingem a honorabilidade e a segurança do Supremo Tribunal Federal e de seus membros; e a verificação da existência de esquemas de financiamento e divulgação em massa nas redes sociais, com o intuito de lesar ou expor a perigo de lesão a independência do Poder Judiciário e ao Estado de Direito.
\end{abstract}

No âmbito desse procedimento investigativo foram cumpridas diversas medidas destinadas a descortinar os autores dos chamados "atos antidemocráticos", dentre as quais, busca e apreensão, afastamento de agentes públicos, etc.

Nesse sentido, apesar de julgado constitucional pelo próprio Supremo Tribunal Federal $^{2}$, o inquérito judicial foi severamente criticado por diversos doutrinadores, notadamente por violar o sistema acusatório consagrado no modelo constitucional, cujo aprofundamento foge do objetivo deste trabalho.

Por outro lado, evidenciou-se a possibilidade de responsabilizar o sujeito que dissemina fake news e promove ataques as instituições democraticamente constituídas.

Nesse contexto, sobreleva anotar que em 16 de fevereiro de 2021, por ocasião da apuração neste mesmo inquérito judicial das fake news, o Deputado Federal Daniel Silveira (PSL-RJ) foi preso em flagrante ${ }^{3}$ delito por ordem do Ministro do Supremo Tribunal Federal Alexandre de Moraes, com referendo da Câmara dos Deputados Federais, tendo em vista que divulgou um vídeo pelas redes sociais contendo fortes críticas e ameaças aos ministros do Supremo Tribunal Federal.

E, neste caso, muito embora não se trate especificamente de divulgação fake news, é certo que a Corte constitucional relativizou o direito à liberdade de expressão. De igual modo, a imunidade material, que também não pode ser invocada a favor do parlamentar para evitar a sua custódia.

Importante ressaltar que igualmente transcende o objeto do presente trabalho analisar o mérito desses dois exemplos citados, utilizados apenas com o escopo de demonstrar que o Supremo Tribunal Federal tem concretamente relativizado o direito à liberdade de expressão.

2 Como pode se depreender por decisão do Pleno na ADPF 572/DF-Rel. Min. Edson Fachin- j. 18/06/2020.

3 Existe polêmica quanto à configuração de estado de flagrância no caso, o que, por fugir do escopo deste trabalho, não será abordado neste artigo. 


\section{MECANISMOS DE REPARAÇÃO E ACESSO À JUSTIÇA}

É preciso deixar induvidoso que o Estado não pode limitar a liberdade de expressão quando a opinião difundida contrariar ou afrontar o pensamento alheio, ainda que seja, a princípio, nutrida por sentimento de repulsa. Esta manifestação, quando exercida num contexto democrático, deve ser sempre preservada. De fato, esta garantia não resguarda apenas as ideias dominantes, mas também aquelas que se revelem aparentemente absurdas. Em contrapartida, a conduta deve ser reprimida quando violar outro bem jurídico, também de jaez constitucional.

Assim, se a notícia inverídica for absolutamente irrazoável, desproporcional e atingir bem jurídico de determinado indivíduo, inequívoco que este poderá propor a correspondente ação civil reparatória por danos materiais e morais, além da ação penal privada, por meio da imputação por crimes contra a honra.

É possível afirmar, nessa ordem de ponderação, que a partir de um único comportamento ilícito, o agente pode violar bens jurídicos protegidos por microssistemas diversos e incorrer em sanções correspondentes a cada ramo jurídico ofendido.

Questão que merece reflexão é se a propagação de fake news violar bem jurídico pertencente a coletividade, chamados de bens transindividuais, com indivíduos indeterminados. Nesse aspecto, é claro que a conduta do agente deve conter todos os elementos inadmitidos pelo direito (ciência inequívoca da mensagem falsa, difundida com o uso de meios fraudulentos e com o objetivo de lesar), sendo essencial verificar como se concretizará o acesso à justiça das pessoas lesadas, notadamente quais são os legitimados e os mecanismos reparatórios da ofensa.

Força reconhecer, logo de início, que a veiculação de notícia falsa, ciente o agente de tal condição, com o objetivo deliberado de causar dano e mediante o uso de fraude, tem potencial para atingir milhares de pessoas, causando-lhes prejuízos incomensuráveis.

Nessa medida, é desnecessário enfatizar a velocidade estratosférica com que as falsas informações são compartilhadas, principalmente por intermédio das mídias sociais e até programas de rádio e TV.

Com efeito, os bens jurídicos mais fundamentais pertencentes à coletividade serão lesados com o uso indiscriminado das fake news, tais como os tutelados pelas esferas eleitoral, ambiental, econômica, da saúde pública, do patrimônio público, dentre outras. 
É induvidoso que as falsas notícias, muito comum no âmbito eleitoral e no ambiente polarizado que se vivencia nos dias atuais, atingem substancialmente o princípio democrático, de jaez constitucional ( $\mathrm{CF}$, art. $\left.1^{\circ}\right)$, além de proporcionar evidente desequilíbrio no processo eleitoral. Especificamente no Brasil, debate-se cotidianamente a utilização desenfreada de boataria às vésperas da eleição, seja municipal ou nacional, com o fim de persuadir o eleitor.

E, nesse vértice, sobreveio orientação do Tribunal Superior Eleitoral, por intermédio da Resolução 23.610/2019, em seu artigo 27, § 1º , no sentido de que "a livre manifestação do pensamento do eleitor identificado ou identificável na internet somente é passível de limitação quando ofender a honra ou a imagem de candidatos, partidos ou coligações, ou divulgar fatos sabidamente inverídicos".

Assim, a partir da proliferação de fake news em período eleitoral e os artifícios empregados pelos fraudadores vão desde a divulgação de vídeo íntimo de candidato até a disseminação de teorias conspiratórias e ataques às minorias.

Por essa razão, diante da gravidade da conduta, com elevado potencial de atingir uma infinidade de eleitores, a Resolução 23.610/2019, coíbe o uso de notícias fraudulentas pela internet, estabelecendo, por consequência, as medidas necessárias a fim de removê-las.

Calha destacar, mais uma vez, que a opinião sobre determinado partido político ou candidato em período eleitoral, ainda que se revele desconectada do senso comum, não pode ser suprimida em razão da liberdade existente no regime democrático. Está abarcada, a toda evidência, as ideias radicais do eleitor, desde que não implique em ilicitude penal.

Poder-se-ia argumentar que a ofensa deliberada e fraudulenta a determinado partido político, candidato ou mesmo sistema de governo, em período pré eleitoral, legitimaria apenas o pretenso candidato a ingressar em juízo para reaver os direitos oriundos da notícia fraudulenta, uma vez que teria sido o único lesado.

Esse argumento, todavia, não convence. É certo que se adotou, a partir da Constituição Federal de 1988, o Estado Democrático de Direito, com prevalência dos direitos fundamentais da pessoa humana. Esta pessoa, como legítima titular do poder estatal, afigurase como verdadeira detentora do princípio democrático, sendo inconcebível pensar em processo eleitoral eivado de fraude sem que se vislumbre ofensa ao povo. Assim, diante da opção por todo o texto constitucional pelo princípio democrático, que se encontra alocado em diversos outros princípios e normas, fácil perceber que a coletividade, por ostentar a qualidade de vítima do processo eleitoral vicioso, deve ser reparada. 
Nesse contexto, com a pandemia do coronavírus ${ }^{4}$, tornou-se comum a disseminação de fake news sobre a saúde humana, o que contribui significativamente para elevar o pânico das pessoas e prejudicar o tratamento da doença.

Tanto que o portal de notícias IG Saúde publicou uma reportagem quanto às sete fake news que mais se alastraram e causaram efetiva desinformação na população durante o ano de 2020 em relação à pandemia, que se destacaram por conter informações falsas, mediante o uso fraudulento, e certamente ocasionaram dano direto ou indireto às pessoas, tais como (IG SAÚDE, 2020): "Vacina contra Covid-19 altera o DNA humano"; "Vacina contra Covid-19 pode inserir um microchip no corpo do vacinado"; "Termômetros infravermelhos causam doenças cerebrais”. Estas notícias, destituídas de qualquer razoabilidade mínima, podem ensejar a imposição de limite jurídico, desde que, por óbvio, contemplem os demais requisitos abordados.

De igual sorte, observa-se a propagação de notícias fabricadas sobre o meio ambiente $^{5}$, com o objetivo deliberado de causar dano, sobre diversos temas relacionado ao aquecimento global, desmatamento, queimadas, dentre outros, que certamente influi negativamente na adoção de medidas preventivas para a correta preservação ambiental.

No âmbito econômico, por sua vez, os efeitos nefastos das fake news são incomensuráveis e podem levar indivíduos tanto à situação de miserabilidade, pelo desemprego, quanto à perda bilionária de ativos no mercado financeiro. Importante frisar que estas notícias vilipendiam o mercado concorrencial, malbaratam um ambiente economicamente harmônico voltado ao cumprimento dos objetivos constitucionais. Por meio delas, agentes econômicos inescrupulosos destorcem a realidade do mercado para auferir lucros de modo injusto e desonesto.

Em contrapartida, fácil perceber que todos estes bens jurídicos lesados se encontram no campo dos interesses transindividuais (como interesse difuso), sejam porque i. extrapolam a órbita individual; ii. seus sujeitos são indetermináveis, isto é, são pertinentes à sociedade como um todo, sendo que não há relação jurídica catalisadora dos indivíduos afetados por esse interesse; iii. o objeto é indivisível, ou seja, a lesão ao bem jurídico tutelado afeta não somente o indivíduo mas toda a coletividade; iv. existe ligação meramente fática a unir os

4 A COVID-19 é uma doença causada pelo coronavírus denominado SARS-CoV-2, que apresenta um espectro clínico variando de infecções assintomáticas a quadros graves. De acordo com a Organização Mundial de Saúde, a maioria (cerca de 80\%) dos pacientes com COVID-19 podem ser assintomáticos ou oligossintomáticos (poucos sintomas), e aproximadamente $20 \%$ dos casos detectados requer atendimento hospitalar por apresentarem dificuldade respiratória, dos quais aproximadamente $5 \%$ podem necessitar de suporte ventilatório.

5 Recentemente o observatório do clima lançou site para combater as fake news sobre meio ambiente. 
sujeitos pulverizados na sociedade, pois ostentam a condição de seres humanos, exatamente nos termos do artigo 81, I, do CDC.

Sob essa perspectiva, identificada a hipótese de lesão aos bens essenciais do meio ambiente, consumidor, patrimônio público e social, bens de valores artísticos, estético e histórico turístico, contra a ordem econômica e economia popular, saúde pública, do regime democrático, dentre outros interesses difusos e coletivos, deve-se utilizar os instrumentos judiciais ou extraprocessuais existentes na Lei de Ação Civil Pública.

A propósito, os interesses transindividuais possuem 'status' de direitos fundamentais consagrados na Constituição Federal de 1988, o que se pode chamar de 'regime constitucional da tutela coletiva', espraiando os seus efeitos em diversos ramos para conceder a máxima eficácia aos bens jurídicos coletivos, como são os atingidos pelas fake news.

Atente-se que a liberdade de expressão do cidadão não pode servir de salvaguarda de práticas ilícitas, de modo que a avaliação concreta dos fatos exige um juízo axiológico do intérprete a fim de que a garantia constitucional não se dissipe no campo do discurso. É possível afirmar, portanto, que as ações coletivas devem ser manejadas com o fim específico de coibir as condutas efetivamente fraudulentas e ilícitas que lesem bens jurídicos transindividuais, jamais àquelas inseridas no espectro libertário do agente e inspiradas no regime democrático.

Assim, caso a falsa notícia propagada pelo cidadão se afaste do mínimo aceitável da razoabilidade e ofenda direitos da coletividade, os órgãos legitimados podem utilizar o microssistema de tutela coletiva, tais como a Lei de Ação Civil Pública, Código de Defesa do Consumidor, Lei Ambiental, etc.

Nesse sentido, calha afirmar que a medida a ser adotada para combater as fake news deverá ter como lastro principal a Lei de Ação Civil Pública e seus regramentos, sem descurar da possibilidade de colmatar eventual vácuo legislativo mediante a utilização de instrumentos em microssistemas semelhantes.

No que pertinente à legitimidade, é certo que são os descritos no artigo $5^{\mathrm{a}}$, da Lei 7.347/85. Nesse viés, para atuar no âmbito eleitoral, o constituinte elegeu o Ministério Público como defensor do regime democrático (CF, art. 127). Além disso, o Promotor de Justiça deve zelar pelo respeito aos Poderes Públicos e dos serviços de relevância pública, aos direitos constitucionalmente assegurados, bem como promover o inquérito civil e a ação civil pública, para a proteção do patrimônio público e social, do meio ambiente e de outros interesses difusos e coletivos (arts. 127 e 129, I e II, CF). 
No mais, exige-se que os legitimados atuem de forma efetiva para minorar os efeitos deletérios da divulgação de fake news, notadamente mediante o uso de mecanismos céleres existentes na Lei 7.347/85 e Código de Processo Civil, tal como a postulação de medidas antecipatórias calcadas na urgência, inclusive, com a cominação de multa diária, em caso de inadimplemento.

É por esse motivo que se admite, na ação civil pública proposta em decorrência de notícia fraudulenta, pedidos cumulados que contemplem a obrigação de fazer, não fazer, além de indenizatórios. Necessário enfatizar que a fixação de danos morais em face da coletividade deve buscar, a um só tempo, reparar a lesão transindividual e impor sanção pedagógica, com o fim de inibir semelhantes práticas vindouras. Almeja-se, com esta demanda, compensar, punir e prevenir.

Em julgamento no Supremo Tribunal Federal, a Ministra Carmen Lúcia, relatora da ADI 4.815/DF, decidiu (BRASIL, 2015):

[...] o dever de respeito ao direito do outro conduz ao de responder nos casos em que, mesmo no exercício de direito legitimamente posto no sistema jurídico, se exorbite causando dano a terceiro. Quem informa e divulga informação responde por eventual excesso, apurado por critério que demonstre dano decorrente da circunstância de ter sido ultrapassada esfera garantida de direito do outro. 2. A liberdade de imprensa - embora amplamente assegurada e com proibição de controle prévio - acarreta responsabilidade a posteriori pelo eventual excesso e não compreende a divulgação de especulação falsa, cuja verossimilhança, no caso, sequer se procurou apurar. 4. Gera dano moral indenizável a publicação de notícia sabidamente falsa, amplamente divulgada, a qual expôs a vida íntima e particular dos envolvidos.

A rigor, inegável os efeitos permanentes e sólidos que a notícia fraudulenta causa na coletividade. Assim, ainda que o magistrado determine ao propagador a imediata retratação pelo mesmo meio de comunicação que a divulgou, sob pena de multa diária, reputa-se inadmissível o retorno ao status quo anterior. Em outros termos "o estrago foi feito e os danos são incomensuráveis".

Diante de tais considerações e segundo os dispositivos legais que regulamentam o caso, deve-se se impor, necessariamente, a correspondente indenização, já que remanesce o interesse pecuniário, com sua tríplice função: a) compensatória; b) punitiva e c) preventiva. 
É de conhecimento que, em geral, as fake news são impulsionadas pela internet, o que autoriza o ente legitimado a fundamentar a ação civil pública na Lei 12.965/2014 (Marco Civil da Internet), notadamente no artigo 19, inclusive quanto ao provedor ${ }^{6}$.

Para além de uma postura passiva, necessita-se de uma atitude pró-ativa de todos os envolvidos, em que se construam malhas de proteção desses interesses indisponíveis. Somente com esta maneira de atuação, estar-se-á concretizando o mandamento constitucional de tutela coletiva, além de garantir o pleno acesso à justiça dos titulares lesados.

Nessa linha, com o fim de coibir uma multiplicidade de formas de caracterização destas condutas ilegais, cometidas em quaisquer níveis, exige-se a adoção de técnicas preventivas sobre as fake news, especialmente de conteúdo educativo, tais como a divulgação de vídeos, palestras, realização de audiências públicas, expedição de recomendações administrativas e demais instrumentos efetivos colocados à disposição dos legitimados.

Nessa medida, somente com a atuação firme e efetiva pode-se enfrentar esta prática ilícita que assola o país, para garantir o pleno acesso à justiça, adequando-se com a $2^{\mathrm{a}}$ e $3^{\mathrm{a}}$ onda preconizada por Mauro Cappelletti (1991, p. 148).

\section{CONCLUSÕES}

A livre manifestação do pensamento, elevada à categoria de direito fundamental na Constituição de 1988, reflete valiosa conquista do Estado Democrático de Direito. Não é crível que se admita a censura como exercício do poder estatal em detrimento da liberdade individual. A exteriorização de ideias é saudável ao ambiente democrático, devendo ser almejada sempre que possível.

A liberdade de expressão contempla posições minoritárias, as destituídas de credibilidade e ainda as aparentemente controversas. Evidentemente, não se pode amordaçar a sociedade com censuras prévias e descabidas. Nesse viés, não parece correto defender o discurso do "politicamente correto" em detrimento da liberdade, porque representa medida antidemocrática.

Deve-se analisar o caso concreto com a finalidade de verificar, com a máxima cautela possível, se a manifestação do agente encontra-se dentro do limite constitucional permitido. Apenas em situações excepcionais, relativiza-se esta extraordinária conquista,

$6 \mathrm{Um}$ provedor de internet consiste em um serviço online administrado por uma pessoa ou empresa que fornece acesso à internet 
especialmente quando importar em ilicitude penal e violar princípios fundamentais da convivência social, como os da igualdade e da dignidade humana, além de atingirem direitos fundamentais das vítimas.

Por esta perspectiva, para caracterizar fake news necessária a presença cumulativa dos seguintes requisitos: a) as mensagens falsas devem ser construídas e divulgadas de maneira consciente e deliberada; b) mediante o uso de artifícios fraudulentos; c) com o objetivo de desinformar e causar danos a pessoas, grupos e instituições.

É preciso ter em mente que o convívio harmonioso e tolerante das pessoas, concretizado a partir da opção ao Estado Democrático de Direitos, somente pode ser idealizado mediante a consagração de uma sociedade pluralista e aberta, que aceite a opinião do próximo, ainda que impopular. Em consequência, exige-se que o intérprete realize criterioso juízo axiológico, com a ponderação dos interesses constitucionais, para aquilatar os reais contornos e limites da liberdade de expressão.

O Supremo Tribunal Federal tem se orientado nesse sentido, em que a liberdade de expressão não detém primazia absoluta, assim como a imunidade parlamentar, especialmente quando afrontar a democracia e outros bens jurídicos fundamentais, consoante entendimento perfilhado no inquérito judicial das fake news.

Quando o exercício da liberdade de expressão foge por absoluto dos limites razoáveis, transbordando dos ideais preconizados pelo constituinte, torna-se legítimo que o Estado, por meio dos entes de persecução, intervenha para reparar a lesão a interesse individual e coletivo.

No mais das vezes, as fraudes empregadas, repita-se, com todos os requisitos danosos, ofendem bens jurídicos de diversos ramos, como a economia, saúde pública, meio ambiente, patrimônio público. Por esta razão, uma vez constatada a violação a estes interesses difusos, os legitimados devem utilizar os mecanismos protetores existentes na Lei de Ação Civil Pública e demais microssistemas, de semelhante natureza, com o fim de alicerçar o combate à informação fraudulenta.

Necessário o manejo dos instrumentos antecipatórios existentes em lei que contemplem a obrigação de fazer, não fazer e pagar. Defende-se, inclusive, que remanesce o interesse indenizatório, como o dano moral coletivo, como forma de compensar, punir e prevenir, ainda que advenha retratação do ofensor.

Não se pode prescindir de uma nova postura séria, coerente e equilibrada de enfrentamento das fake news, primeiro para restringir a liberdade de expressão apenas e 
quando afrontar outros valores tutelados pela Constituição Federal e, segundo, para promover debates públicos, com instruções pedagógicas, seja de maneira preventiva ou repressiva.

Dessa forma, restar-se-á concretizada a tão almejada garantia de acesso à justiça, como o mecanismo célere e efetivo de proteger os bens jurídicos transindividuais.

Por fim, importante ressaltar que as ideias neste trabalho expostas, constituem uma reflexão e não uma conclusão definitiva sobre tão difícil e delicado tema.

\section{REFERÊNCIAS}

ALVES, Marco Antônio Souza Alves; MACIEL, Emanuella Ribeiro Halfeld. O fenômeno das fake news: definição, combate e contexto. Revista Internet \& Sociedade, n. 1, v. 1, fev. 2020. Disponível em: <https://revista.internetlab.org.br/o-fenomeno-das-fake-news-definicaocombate-e-contexto/>. Acesso em 07 out. 2020.

BARROSO, Luís Roberto. Liberdade de expressão, censura e controle da programação de televisão na Constituição de 1988. Revista dos Tribunais, v. 90, n. 790, 2001, p. 131.

BINENBOJM, Gustavo. Fake news, liberdade de expressão e a defesa da democracia. Youtube, 22 jun. 2020. Disponível em: $<$ https://www.youtube.com/watch?v=wHDFS3yD8k>. Acesso em: 06 out. 2020.

CAPPELLETTI, Mauro. O acesso à justiça e a função do jurista em nossa época. Revista de Processo. São Paulo: Editora Revista dos Tribunais, n. ${ }^{\circ}$ 61, p. 148-9, 1991.

BRASIL. Supremo Tribunal Federal. Ação Direta de Inconstitucionalidade 4.815 Distrito Federal. Ministra Relatora Cármen Lúcia. Julgamento em 10 de junho de 2015. Disponível em: < http://redir.stf.jus.br/paginadorpub/paginador.jsp?docTP=TP\&docID=10162709>. Acesso em: 01 mar. 2021.

. Supremo Tribunal Federal. Inquérito 4.781 Distrito Federal. Ministro Alexandre de Moraes. Decisão de 26 de maio de 2020. Disponível em: $<$ http://www.stf.jus.br/arquivo/cms/noticiaNoticiaStf/anexo/mandado27maio.pdf $>$. Acesso em: 23 fev. 2021.

Supremo Tribunal Federal. Habeas Corpus 82.424-2. Julgamento em 17 de setembro de 2003. Disponível em:

$<$ http://redir.stf.jus.br/paginadorpub/paginador.jsp?docTP=AC\&docID=79052> . Acesso em: 01 mar. 2021. 
CAPPELLETTI, Mauro. O acesso à justiça e a função do jurista em nossa época. Revista de Processo. São Paulo: Editora Revista dos Tribunais, n. ${ }^{\circ}$ 61, p. 148-9, 1991.

CARVALHO, L. G. Grandinetti Castanho de. Direito de Informação e liberdade de expressão. Rio de Janeiro: Renovar, 1999, p. 24.

CONSELHO FEDERAL DE MEDICINA. Parecer 04/2020. Disponível em:

$<$ https://portal.cfm.org.br/artigos/o-conselho-federal-de-medicina-e-a-covid-19/>. Acesso em: 01 abr. 2021.

G1. Associação médica diz que uso da cloroquina e outros remédios sem eficácia contra Covid 19 deve ser banido. Disponível em:

$<$ https://g1.globo.com/bemestar/coronavirus/noticia/2021/03/23/amb-diz-que-uso-decloroquina-e-outros-remedios-sem-eficacia-contra-covid-19-deve-ser-banido.ghtml $>$. Acesso em: 01 abr. 2021

GARCIA, Guiomari Garson da Costa. Estado Democrático de Direito e liberdade de expressão e informação. Revista de Direito Constitucional e Internacional, v. 11, n. 42, p. 288-289, jan./mar. 2003.

IG SAÚDE. Confira as 7 fake news mais perigosas sobre a pandemia de Covid-19. Disponível em: <https://saude.ig.com.br/coronavirus/2020-12-23/2020-confira-as-7-fakenews-mais-perigosas-sobre-a-pandemia-de-covid-19.html $>$. Acesso em: 20 jan. 2021.

MÉDICOS PELA VIDA. Manifesto pela vida. Médicos do tratamento precoce Brasil. Disponível em: <https://medicospelavidacovid19.com.br/manifesto/>. Acesso em: $01 \mathrm{abr}$. 2021.

SARMENTO, Daniel. A liberdade de expressão e o problema do hate speech. Revista de Direito do Estado. Rio de Janeiro: Renovar, ano 1, n. 4, p. 58, out./dez. 2006.

Dignidade da Pessoa Humana. 2. ed. Belo Horizonte: Editora Fórum. 2019, p. 83. 